\title{
Lunar cycle may have an effect on Shock Wave Lithotripsy related pain outcome
}

\author{
Hüsnü Tokgöz ${ }^{1}$, Soner Yalçınkaya ${ }^{1}$, Ekrem İslamoğlu ${ }^{1}$, Kaan Karamık ${ }^{1}$, Özlem Tokgöz ${ }^{2}$ and Murat \\ $\operatorname{Savaş}^{1}$
}

Ghana Med J 2017; 51(4):181-186 DOI: http://dx.doi.org/10.4314/gmj.v51i4.6

Antalya Training and Research Hospital, Departments of Urology ${ }^{1}$ and Radiology ${ }^{2}$, Antalya, Turkey

Corresponding author: Dr. Hüsnü Tokgöz

E-mail: $\underline{\text { h tokgoz@ }, \text { hotmail.com }}$

Conflict of interest: None Declared

\section{SUMMARY}

Objectives: We tried to investigate the effects of lunar phase on Shock Wave Lithotripsy (SWL) related pain. In addition, correlation of various clinical parameters with the pain perception during SWL procedure, were also investigated.

Methods: A total of 378 patients who underwent first SWL sessions for renal or ureteral stones were prospectively enrolled in the study. The degree of pain perception during the procedure was evaluated with 10-point visual analog scale (VAS) and pain questionnaires. The date of SWL was allocated to dates and times of lunar phases as: newmoon, waxing crescent, first quarter, waxing gibbus, fullmoon, waning gibbus, last quarter and waning gibbus.

Results: Mean VAS scores in first quarter $(2,41 \pm 1,06)$ were significantly lower when compared to mean VAS scores in waning crescent $(3,58 \pm 1,83)$ and waning gibbus $(3,42 \pm 1,98)(p=0,005$ and 0,041 , respectively). No statistically significant differences were observed when other lunar phases were compared between each other. Mean pain scores were not affected from gender, age, body mass index (BMI) and stone characteristics (stone laterality, burden and location).

Conclusions: SWL procedure performed in first quarter of the lunar phase may become less painful. To the best of our knowledge, this is the first study which evaluated the effect of lunar phase on post-SWL pain outcome. Thus, additional randomized studies with larger series may be more informative.

Keywords: lunar phase, lithotripsy, pain, predictive factors, urinary stones

\section{INTRODUCTION}

Shock Wave Lithotripsy (SWL) is accepted as a less invasive approach and most guidelines recommend it as the first-line treatment if location and size of the calculi are appropriate for spontaneous passage of fragmented particles ${ }^{1}$. As the SWL session is undertaken without anesthesia, shock wave-related pain is one of the most significant side effects of SWL. Although, with the development of SWL technology, analgesic requirements during the procedure have significantly decreased, proper pain management to ensure success and patient satisfaction is essential. However, pain perception received during a SWL session, is a multi-dimensional concept and may be affected from various factors including a wide variety of medical conditions. In addition, psychosocial factors such as expectations, emotions, and an individual's unique learning history may result in a variety of pain perception. Biological variables, including hormonal status and cardiovascular reactivity, may add further differences ${ }^{2-4}$. Seasonal, lunar and circadian rhythms may also affect human biology.
Although the seasonal and circadian rhythms have been fairly well described, little is known about the effects of the lunar cycle on the behavior and physiology of humans. Due to barometric pressure, geomagnetic and gravitational changes during different phases of the moon, human behaviour should be affected ${ }^{5,6}$. In various studies, the effect of lunar cycle on human behaviour have been investigated. Moon's influence on suicides, crimes, traffic accidents, cardiopulmonary resuscitations, birth rates, renal colic, postoperative complications, patient survival after the therapy, admittance to hospitals and emergency units because of various causes (cardiovascular and acute coronary events, variceal hemorrhage, diarrhea, urinary retention) have been already investigated ${ }^{6-14}$. Although, most of the reports found no correlations, related to urology clinical practice, some researchers observed that, renal colic frequency might be correlated with lunar calendar ${ }^{15}$. From this point of view, for the first time in current literature, the effect of lunar cyle on post-SWL pain has been studied. 
In our prospective study, we tried to investigate the effects of lunar phase on SWL related pain outcome. In addition, correlation of various clinical parameters such as patient age, gender, body mass index (BMI) and stone characteristics with the pain perception during SWL procedure, were also investigated.

\section{METHODS}

After the approval of the hospital ethic committee was obtained, we prospectively evaluated a total of 378 patients who underwent first session of SWL for renal/ ureteral stones. Before the procedure we evaluated patients with urinalysis, urine culture, coagulation profile and serum creatinine level. Radiological imaging was done by noncontrast helical computed tomography and, all parameters related with stone characteristics (stone location, side, burden) were determined by an experienced radiologist. Exclusion criteria were signs and symptoms of active urinary tract infection, pregnancy, moderate to severe hydronephrosis, renal insufficiency with serum creatinine $>2.5 \mathrm{mg} / \mathrm{dL}$, multiple and/ or bladder and/ or radiolucent stones. Patients who received auxiliary procedures, such as percutaneous nephrostomy/ double-J catheter insertion or endoscopic treatment before SWL session, patients who had difficulty in understanding the pain scoring systems, and patients who underwent second or third sessions of their SWL procedure were also excluded.

The date of SWL was allocated to the dates and times of the lunar phases defined as: Newmoon, waxing crescent, first quarter, waxing gibbus, fullmoon, waning gibbus, last quarter and waning gibbus. Sun illuminates the side of the moon facing Earth. The portion of this hemisphere that is visible to us on Earth can vary from about $100 \%$ (full moon) to $0 \%$ (new moon). Between these 2 phases, the degree of illumination varies. This parameter was defined as "illumination percent" in our trial. The calendar month that we already use is about 30.44 days, while the Moon's phase cycle repeats on average every 29.53 days. Therefore, the timing of the Moon's phases shifts by an average of almost one day for each successive month. So, a lunar year has 354 days. The eight phases of the moon were categorized; new moon to waxing crescent (0 to 3.69), wax crescent to first quarter (3.69-7.38), first quarter to waxing gibbous (7.38-11.07), waxing gibbous to full moon (11.07-14.76), full moon to waning gibbous (14.76-18.45), waning gibbous to last quarter (18.45-22.14), last quarter to waning crescent (22.14-25.83), and waning crescent to new moon (25.83-29.53). "Lunar day" was also calculated in the same manner with ordinary used computer programs.
Just before the procedure, patient data including age, gender, weight and height were collected. The BMI was calculated for each patient by dividing weight in kilograms by height in meters squared. The stone burden was calculated by multiplying the largest length of the stone by the shortest perpendicular length and was recorded in square millimeters.

By the same technician under the supervision of a urologist, all patients underwent first session of their SWL procedure using EMD E-1000® (EMD Medical, Turkey) Lithotripter, an electrohydraulic unit that permits us to use X-ray for stone focusing. All patients were given pain therapy with diclofenac sodium $75 \mathrm{mg}$. Intramuscularly (I.M.), 30 minutes before the SWL session. The patients were previously informed not to use oral/ intravenous/ intramuscular analgesics at least in 3 days before the procedure. If the patient scheduled for SWL suffered pain (renal colic) at the day of the procedure, the SWL session was postponed.

In 2010, we designed a randomized, double-blind clinical trial to assess the analgesic efficacy of single dose IM injection of $50 \mathrm{mg}$. dexketoprofen compared with single dose IM injection of $75 \mathrm{mg}$. diclofenac sodium, and we observed that, severity of post-SWL pain was better tolerated with dexketoprofen trometamol. ${ }^{16}$ But, in current trial, we decided to use diclofenac sodium. It is among the most widely used non-steroidal antiinflammatory drugs with lower side effects. Pharmacodynamic studies related with diclofenac sodium reported that, after i.m. administration of $75 \mathrm{mg}$ diclofenac sodium, maximum plasma concentrations had been reached approximately in 25 minutes. ${ }^{17,18}$ Thus, in our trial, injections were made 30 minutes before the procedure as a routine part of the treatment. No side effect related with the drug was observed in our study population.

The number of shock waves (x 2500) delivered for each patient and energy (13 to 19 kilovolts with constant gradual increase) used in each SWL session were same for each patient. Immediately after the procedure, the degree of pain perception was rated by the patients using a 10 -point visual analog scale (VAS), and patients were asked about the experience and to rate the severity of pain as no, minor, tolerable, and intolerable.

All analyses were performed using IBM SPSS Statistics Version 20.0 statistical software package (IBM Corp. Released 2011. IBM SPSS Statistics for Windows, Version 20.0. Armonk, NY: IBM Corporation). Categorical variables were expressed as numbers and percentages, whereas continuous variables were summarized as mean and standard deviation. 
To evaluate the correlations between measurements, Pearson correlation coefficient was used. Differences in mean VAS scores in each parameters were assessed with Mann-Whitney U test. For the evaluation of differences in categorical variables, chi square test was used. The statistical level of significance for all tests was considered to be 0.05 .

\section{RESULTS}

Demographic data and stone characteristics were demonstrated in Table 1. Mean VAS scores were comparable between males and females. Similarly, VAS scores were comparable for renal and ureteral; and rightand left-sided urinary stones. When a cut-off value for BMI was taken as $30 \mathrm{~kg} / \mathrm{m}^{2}$, no statistically significant difference was observed between groups. When the cutoff value for stone burden was accepted as $100 \mathrm{~mm}^{2}$, no significant difference was observed.

Table 1 Demographic data and stone characteristics $(\mathrm{n}=378)$

\begin{tabular}{|c|c|c|}
\hline \multicolumn{3}{|l|}{ Variables } \\
\hline Age (years)* & & $41.87 \pm 1.33$ \\
\hline Weight $(\mathrm{kg})^{*}$ & & $76.20 \pm 1.49$ \\
\hline Height $(\mathrm{cm})^{*}$ & & $167.76 \pm 11.20$ \\
\hline BMI $\left(\mathrm{kg} / \mathrm{m}^{2}\right)^{*}$ & & $27.58 \pm 1.08$ \\
\hline Stone burden & & $114.59 \pm 92.27$ \\
\hline Gender & $\begin{array}{l}\text { Female } \\
\text { Male }\end{array}$ & $\begin{array}{l}136(36 \%) \\
242(64 \%)\end{array}$ \\
\hline Side of stone & $\begin{array}{l}\text { Right } \\
\text { Left }\end{array}$ & $\begin{array}{l}191(50.5 \%) \\
187(49.5 \%)\end{array}$ \\
\hline Stone location & $\begin{array}{l}\text { Renal pelvis } \\
\text { Upper calyx } \\
\text { Middle calyx } \\
\text { Lower calyx } \\
\text { Ureter } \\
\quad \text { Upper } \\
\quad \text { Middle } \\
\quad \text { Lower }\end{array}$ & $\begin{array}{l}142(37.6 \%) \\
30(7.9 \%) \\
29(7.7 \%) \\
18(4.8 \%) \\
159(42.1 \%) \\
111(29.4 \%) \\
37(9.8 \%) \\
11(2.9 \%)\end{array}$ \\
\hline
\end{tabular}

* Values are presented as means \pm standard deviations

However, when mean VAS scores were compared with regard to the phases of the moon, first quarter was found to be significantly the least painful period (Table 2). No statistically significant correlation was found between mean VAS scores and "Illumination percent", moon age, BMI, stone burden or patient age (Table 3).
Table 2 Descriptive statistics for moon phases, BMI, gender and stone characteristics

\begin{tabular}{lll}
\hline Variables & & $\begin{array}{l}\text { [VAS } \\
(\text { Mean } \pm \text { SD) }\end{array}$ \\
\hline Moon phase & & \\
\hline New moon & $(\mathrm{n}=10)$ & $3.00 \pm 1.63$ \\
Waxing crescent & $(\mathrm{n}=90)$ & $3.23 \pm 1.76$ \\
First quarter & $(\mathrm{n}=17)$ & $2.41 \pm 1.06 \dagger \dagger$ \\
Waxing gibbus & $(\mathrm{n}=73)$ & $3.20 \pm 1.77$ \\
Full moon & $(\mathrm{n}=11)$ & $3.00 \pm 1.61$ \\
Waning gibbus & $(\mathrm{n}=71)$ & $3.42 \pm 1.98$ \\
Last quarter & $(\mathrm{n}=13)$ & $2.76 \pm 1.36$ \\
Waning crescent & $(\mathrm{n}=93)$ & $3.58 \pm 1.83$
\end{tabular}

\begin{tabular}{lll}
\hline BMI $\left(\mathbf{k g} / \mathbf{~ m}^{2}\right)$ & & \\
\hline$<30$ & $3.28 \pm 1.81$ & 0.936 \\
$\geq 30$ & $3.26 \pm 1.68$ &
\end{tabular}

\begin{tabular}{lll}
\hline Gender & & \\
\hline Female & $3.38 \pm 1.83$ & 0.320 \\
Male & $3.22 \pm 1.76$ & \\
& &
\end{tabular}

\begin{tabular}{lll} 
Stone location & & \\
\hline Renal & $3.22 \pm 1.74$ & 0.586 \\
Ureteral & $3.36 \pm 1.85$ & \\
& & \\
\hline Stone burden $\left(\mathbf{m m}^{2}\right)$ & & \\
& & 0.461 \\
$>100$ & $3.34 \pm 1.79$ & \\
\hline
\end{tabular}

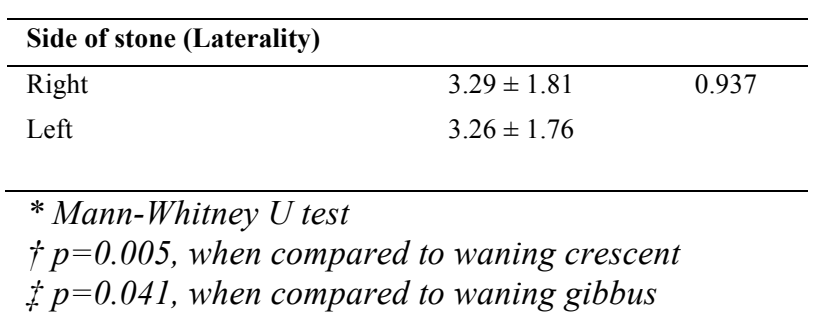

For the whole study population, mean VAS scores in "no pain" $(\mathrm{n}=6)$, "minor pain" $(\mathrm{n}=181)$, "tolerable pain" $(\mathrm{n}=164)$ and "intolerable pain" $(\mathrm{n}=27)$ groups were $1.66 \pm 1.03 ; 2.40 \pm 0.76 ; 3.68 \pm 1.59$ and $7.11 \pm 2.01$, respectively. However, no statistically significant difference was demonstrated when moon phases were compared according to pain questionnaire results (Table 4). During the study period, no major complication such as bleeding was encountered, and none of the patients required an inpatient stay after SWL 
Table 3 Correlation of variables with mean VAS scores

\begin{tabular}{lll}
\hline Variables & Correlation coefficient & $\boldsymbol{p}$ value* \\
\hline Illumination (\%) & -0.017 & 0.741 \\
Moon age (days) & 0.086 & 0.095 \\
Age & -0.022 & 0.667 \\
Weight & -0.078 & 0.131 \\
Height & -0.019 & 0.714 \\
BMI & -0.028 & 0.591 \\
Stone burden & -0.019 & 0.715 \\
\hline
\end{tabular}

* Pearson correlation analysis

Table 4 Results of pain questionnaire according to moon phases

\begin{tabular}{|c|c|c|c|c|c|c|c|c|c|}
\hline $\begin{array}{l}\text { Pain question- } \\
\text { naire }(n-\% \text { of } \\
\text { total) }\end{array}$ & $\begin{array}{l}\text { New } \\
\text { moon } \\
(n=10)\end{array}$ & $\begin{array}{l}\text { Waxing } \\
\text { crescent } \\
(n=90)\end{array}$ & $\begin{array}{l}\text { First } \\
\text { quarter } \\
(\mathbf{n}=17)\end{array}$ & $\begin{array}{l}\text { Waxing } \\
\text { gibbus } \\
(n=73)\end{array}$ & $\begin{array}{l}\text { Full } \\
\text { moon } \\
(n=11)\end{array}$ & $\begin{array}{l}\text { Waning } \\
\text { gibbus } \\
(n=71)\end{array}$ & $\begin{array}{l}\text { Last } \\
\text { quarter } \\
(n=13)\end{array}$ & $\begin{array}{l}\text { Waning } \\
\text { Crescent } \\
(n=93)\end{array}$ & p-value* \\
\hline & & & & & & & & & 0.705 \\
\hline No pain & $0(0 \%)$ & $2(0.5 \%)$ & $1(0.3 \%)$ & $2(0.5 \%)$ & $0(0 \%)$ & $0(0 \%)$ & $1(0.3 \%)$ & $0(0 \%)$ & \\
\hline Minor pain & $6(1.6 \%)$ & $45(11.9 \%)$ & $8(2.1 \%)$ & $34(9 \%)$ & $6(1.6 \%)$ & $31(8.2 \%)$ & $8(2.1 \%)$ & $43(11.4 \%)$ & \\
\hline Tolerable pain & $3(0.8 \%)$ & $40(10.6 \%)$ & $7(1.9 \%)$ & $33(8.7 \%)$ & $4(1.1 \%)$ & $32(8.5 \%)$ & $4(1.1 \%)$ & $41(10.8 \%)$ & \\
\hline Intolerable pain & $1(0.3 \%)$ & $3(0.8 \%)$ & $1(0.3 \%)$ & $4(1.1 \%)$ & $1(0.3 \%)$ & $8(2.1 \%)$ & $0(0 \%)$ & $9(2.4 \%)$ & \\
\hline
\end{tabular}

* chi square test

\section{DISCUSSION}

Although, diclofenac sodium does not seem the perfect choice for pain management in SWL treated patients, it provides considerable amount of analgesia. Because, in current study, for the whole study group, mean pain score was $3.28 \pm 1.79$. In addition, among 378 cases, only $27(7.1 \%)$ cases defined the SWL procedure as intolerable (Table 4). So, we think that, adequate pain relief and patient comfort could be achieved with diclofenac sodium.

Up to $18 \%$ of German population, believe that the moon cycle influences the follow up of diseases ${ }^{13}$. Holzheimer et al. ${ }^{13}$ investigated the influence of lunar phase on surgical quality, but they could not find any correlation of postoperative complications with the lunar phase. Similarly, Komann et al. ${ }^{19}$ observed that lunar phases have no effect on post-surgical pain or its side effects. Related to urology practice, May et al. ${ }^{5}$ studied the effect of lunar phase on quality of radical cystectomy. They could not find any significant difference in terms of the perioperative mortality rates, early re-operation rates, postoperative complications and progression-free survivals. Researchers from Switzerland, investigated whether the incidence of symptomatic renal colics would increase at the time of the full and new moon because of increased lunar gravitational forces ${ }^{20}$. However, they could not observe any statistically significant difference.
In contrast, Ghalae et al. ${ }^{15}$ evaluated renal colic frequency in different seasons and around full moon. They did not find any correlation with solar calendar.

But, among 1481 patients with renal colic, most of the admissions to emergency department were on day 15 in lunar calendar $(\mathrm{p}<0.05)$. So, on full moon period, significantly increased admissions for renal colic were noticed. In addition, various studies have been published demonstrating positive correlations between the full moon and incidence of psychological crisis, suicide, child behavior disorders, accidents and injuries ${ }^{21-24}$. Ghiandoni et al. ${ }^{25}$ showed a significant connection between the distribution of spontaneous full-term deliveries and the lunar month. Mikulecky et $\mathrm{al}^{26}$ also revealed that, the maximal occurrence of gout attacks coincides with the peaking lunisolar tidal effect. Thus, we cannot fully neglect the effect of lunar phase on human body. We observed statistically significant differences only in "first quarter" period (Table 2). Mean VAS score for this moon period was only 2.4 points, which is low enough (Table 2$)$. Only 1 (5.9\%) patient had intolerable pain during this period (Table 4). Of course, this data might be coincidental and must be supported by randomized trials with larger series, but according to the results of this trial, we can say that SWL performed in first quarter may be less painful. 
In our study, pain scores during the SWL procedures, were not affected by stone characteristics like laterality, location and burden. Similarly, patient age, gender and BMI were not found to be the predicters of SWL related pain outcome (Tables 2 and 3). Six years ago, we published a paper investigating the correlation of those parameters with post-SWL pain ${ }^{27}$. We evaluated 88 cases who underwent 165 SWL sessions for renal and ureteral calculi, and we noticed that SWL session, stone burden and gender might alter post-SWL pain. Although, in former study, the differences in mean VAS scores between groups (male/ female, first/ second/ third session, $>100 \mathrm{~mm}^{2} / \leq 100 \mathrm{~mm}^{2}$ ) were approximately 1 point, significant $p$ values were reached. In current study, we excluded cases undergoing second/ third sessions of their SWL therapy in order to eliminate the possible effect of session on pain outcome. Current study was including a larger study population, and we did not observe any gender and burden effect. We already mentioned in our paper that this result could be coincidental. Because, although the $\mathrm{p}$ value was significant, the correlation coefficient for stone burden was 0.176 , concluding mild correlation ${ }^{27}$. Similarly, Franceschi et al. ${ }^{28}$, evaluated possible predictive factors for severe pain leading to an indication for analgesia during SWL and concluded that, pain received during SWL cannot be predicted by age, anxiety state, side of the stones and size, diameter of the contact between patient and convergence dome of the lithotripter. In contrast, they observed that the size and location of the stone were correlated with the pain level. The superior caliceal, middle caliceal and pelvic stones were significantly the most painful calculi ${ }^{28}$. In another study, Oh SJ et al. ${ }^{29}$ observed that, subjective pain score was not affected by laterality, size of stone; but was affected by patient age, gender and location of stone. So, for today, it is still difficult to conclude which factors would predict SWL related pain outcome. Because, as we discussed in limitations section, pain is a subjective phenomena.

Potential limitations to our study should be considered. First of all, visual analog scale is easy, commonly used but a subjective way in the evaluation of pain perception. Secondly, the cause of pain is multifactorial in nature and, we were unable to discriminate renal capsular pain and pain caused by movement of stone during SWL, from cutaneous or costal pains (for renal stones). Thirdly, pain itself is a very subjective phenomenon. For the same type of intervention, the degree of pain experienced varies from patient to patient and, can be affected by many factors such as age, personality, education, social status, patient's knowledge.
Although, our study has a large study population including 378 cases, some subgroups related to moon phases have relatively small sample size. Future studies with randomization may give more conclusive data.

In conclusion, to the best of our knowledge, our study is the first, that investigated the effect of lunar phases on post-SWL related pain outcome. SWL procedure performed in first quarter of the lunar phase may become less painful. However, pain perception during SWL procedure were not affected from patient age, gender, BMI and stone characteristics (side, location and burden).

\section{REFERENCES}

1. Tiselius HG, Ackermann D, Alken P, Buck C, Conort P, Gallucci M; Working Party on Lithiasis, European Association of Urology. Guidelines on urolithiasis. Eur Urol 2001; 40 (4): 362-71.

2. Zatrick DF, Dimsdale JE. Cultural variations in response to painful stimuli. Psychosomatic Med 1990; 52 (5): 544-57.

3. Fillingim RB, Maixner W. Gender differences in the responses to noxious stimuli. Pain Forum 1995; 4: 209-22.

4. Riley JL, Robinson ME, Wise EA, Price DD. A meta-analytic review of pain perception across the menstrual cycle. Pain 1999; 81 (3): 225-35.

5. May M, Braun KP, Helke C, Richter W, Vogler H, Hoschke B, Siegsmund M. Lunar phases and zodiac signs do not influence quality of radical cystectomy-a statistical analysis of 452 patients with invasive bladder cancer. Int Urol Nephrol 2007; 39 (4): 1023-1030.

6. Alves DW, Allegra JR, Cochrane DG, Cable G. Effect of lunar cycle on temporal variation in cardiopulmonary arrest in seven emergency departments during 11 years. Eur J Emerg Med 2003; 10 (3): $225-8$.

7. Gutierrez-Garcia JM, Tusell F. Suicides and the lunar cycle. Psychol Rep 1997; 80 (1): 243-50.

8. Martin SJ, Kelly IW, Saklofske DH. Suicide and lunar cycles: a critical review over 28 years. Psychol Rep 1992; 71 (3 pt 1): 787-95.

9. Abell GO, Greenspan B. Human births and the phase of the moon. N Engl J Med 1979; 300 (2): 96.

10. Arliss JM, Kaplan EN, Galvin SL. The effect of the lunar cycle on frequency of births and birth complications. Am J Obstet Gynecol 2005; 192 (5): 14624.

11. Exadaktylos AK, Hauser S, Luterbacher J, Marti U, Zimmermann H, Studer UE. The moon and the stones. Can the moon's attractive forces cause renal colic? J Emerg Med 2002; 22 (3): 303-5. 
12. Smolle J, Prause G, Kerl H. A double-blind, controlled clinical trial of homeopathy and an analysis of lunar phases and postoperative outcome. Arch Dermatol 1998; 134 (11): 1368-70.

13. Holzheimer RG, Nitz C, Gresser U. Lunar phase does not influence surgical quality. Eur J Med Res 2003; 8 (9): 414-8.

14. Peters-Engl C, Frank W, Kerschbaum F, Denison U, Medl M, Sevelda P. Lunar phases and survival of breast cancer patients-a statistical analysis of 3,757 cases. Breast Cancer Res Treat 2001; 70 (2): $131-5$.

15. Ghalae HMG, Zare S, Choopanloo M, Rahimian R. The Lunar Cycle: Effects of Full Moon on Renal Colic. Urol J 2011; 8 (2): 137-40.

16. Tokgoz H, Yurtlu S, Hanci V, Turksoy O, Erol B, Akduman B, Mungan A. Comparison of the analgesic effects of dexketoprofen and diclofenac during shockwave lithotripsy: a randomized, double-blind clinical trial. J Endourol 2010; 24 (6): 1031-5.

17. Ojha A, Shep D, Nivsarkar M, Patel S, Jaiswal V, Padh H. Pharmacokinetic profile of a new formulation of injection diclofenac designed for intradeltoid use. Expert Opin Pharmacother 2009; 10 (4): 517-22.

18. Derendorf H, Mullersman G, Barth J, Grüner A, Möllmann H. Pharmacokinetics of diclofenac sodium after intramuscular administration in combination with triamcinolone acetate. Eur $J$ Clin Pharmacol 1986; 31 (3): 363-5.

19. Komann M, Weinmann C, Meissner W. Howling at the moon? The effect of lunar phases on postsurgical pain outcome. Br J Pain 2014; 8 (2): 72-7.
20. Arampatzis S, Thalmann GN, Zimmermann $\mathrm{H}$, Exadaktylos AK. Lunar tractive forces and renal stone incidence. Emerg Med Int. 2011; 2011: 813460 doi: $10.1155 / 2011 / 813460$.

21. Snoyman P, Holdstock TL. The influence of the sun, moon, climate and economic condition on crisis incidence. J Clin Psychol 1980; 36 (4): 884-93.

22. Lieber AL. On the moon again. Am J Psychiatry 1975; 132 (6): 669-70.

23. Russell MB, Bernal ME. Temporal and climatic variables in naturalistic observation. J Appl Behav Anal 1977;10 (3): 399-405.

24. Nogueria DP. Effect of lunar cycle on human behaviour. J R Soc Med 1982; 75 (9): 753-4.

25. Ghiandoni G, Secli R, Rocchi MB, Ugolini G. Does lunar position influence the time of delivery? A statistical analysis. Eur J Obstet Gynecol Reprod Biol 1998; 77 (1): 47-50.

26. Mikulecky M, Rovensky J. Gout attacks and lunar cycle. Med Hypotheses 2000; 55 (1): 24-5.

27. Tokgoz H, Hanci V, Turksoy O, Erol B, Akduman B, Mungan NA. Pain Perception During Shock Wave Lithotripsy: Does It Correlate With Patient and Stone Characteristics? J Chin Med Assoc 2010; 73 (9): 477-82.

28. Franceschi A, Rozada P, Galerneau V, Senant J, Boureau F, De Fourmestraux N, Sibert L, Grise P. Pain and extracorporeal lithotripsy for calculi of the upper urinary tract. Ann Urol 1991; 25 (3): 131-7.

29. Oh SJ, Ku JH, Lim DJ, Byun SS, Kim HH. Subjective pain scale and the need for analgesia during shock wave lithotripsy Urol Int 2005;74 (1): 54-7 